DOI: https://doi.org/10.15688/lc.jvolsu.2017.4.8

UDC 340.12

LBC 67.400 .4

\title{
THE ESSENCE OF A STATE: A TELEOLOGICAL APPROACH
}

\author{
Nikolay I. Grachev \\ Volgograd State University, Volgograd, Russian Federation
}

\begin{abstract}
Introduction: the nature of a state in the modern theory of state and law is often reduced to its social purpose, which greatly impoverishes the category of the essence and does not allow moving on the path of knowledge of the most profound moment of the essence of a state. The purpose of the study is to find the most adequate approach to the process of cognition of a state in which, as shown by the representatives of the dialectical method, the human mind, infinitely deepening moves from lying on the surface phenomena to their essence, from the essence of the first order to the essence of the second order, etc. without end until the basis of the phenomenon, which is understood as the most profound moment of its essence. The methodological framework for the work is a philosophical analysis of the categories of "essence" and "phenomenon", a collection of the dialectical, metaphysical and systematic research methods, as well as the teleological approach. In accordance with it all the objects and phenomena of the objective world contain the potential, inherent purpose of their existence that they seek to implement in the course of their development. Results: there is given a reason for the author's viewpoint with respect to the original reason of existence of a state as a politically organized society, the purposes of its existence and the hierarchy of the values which it is intended to serve in the course of its existence and development. Conclusions: the idea of a full de facto sovereignty is a political essence of a state, including all the remaining levels of its nature - the anthropological, ontological, social, and national-cultural ones.

Key words: essence, phenomenon, purpose, state, essence of a state, goals of a state, form and content of a state, sovereignty.
\end{abstract}

УДК 340.12

ББК 67.400 .4

\section{СУЩНОСТЬ ГОСУДАРСТВА: ТЕЛЕОЛОГИЧЕСКИЙ ПОДХОД}

\author{
Николай Иванович Грачев \\ Волгоградский государственный университет, г. Волгоград, Российская Федерация
}

\begin{abstract}
Введение: сущность государства в современной теории государства и права часто сводят к его социальному назначению, что в значительной степени обедняет категорию сущности и не позволяет продвинугься по пуги познания наиболее глубокого момента сущности государства. Цель исследования состоит в нахождении наиболее адекватного подхода к самому процессупознания государства, в котором, как показали представители диалектического метода, человеческая мысль, бесконечно углубляясь, движется от лежащих на поверхности явлений к их сущности, от сущности первого порядка к сущности второго порядка и т. д. без конца вплоть до самой основы явления, под которой понимается наиболее глубокий момент его сущности. Методологическую основу работы составили философский анализ категорий «сущность» и «явление», совокупность диалектического, метафизического и системного методов исследования, а также телеологический подход. В соответствии с ним все предметы и явления объективного мира содержат в себе потенциальную, внутренне присущую им цель существования, которую они стремятся ^ реализовать в процессе своего развития. Результаты: аргументирована авторская позиция относительно изначальㄱ. ного основания бытия государства как политически организованного общества, целей его существования и иерарх хии ценностей, которым оно призвано служить в процессе своего существования и развития. Выводы: в идее полного фактического суверенитета заключается политическая сущность государства, включающая в себя все ос急 тальные уровни его сущности, - антропологический, онтологический, социальный и национально-культурный.

Ключевые слова: сущность, явление, цель, государство, сущность государства, цели государства, форма и содержание государства, суверенитет.
\end{abstract}




\section{Введение}

Под сущностью любого явления понимаются его наиболее важные, необходимые элементы, качества и признаки, раскрывающие его содержание, наиболее важные и устойчивые связи, а также закономерности (законы) его бытия и развития, которые и предопределяют все его качества, имманентные ему цели, признаки, причины появления, существования и конечные объективные результаты бытия (историческую судьбу) [14, с. 638]. Из этого следует, что сущность государства невозможно свести к его социальному назначению, как это часто делается в литературе по теории государства и права. Также сущность государства не может быть постигнута юриспруденцией, если она не выйдет за пределы юридических категорий.

Государство необходимо рассматривать, с одной стороны, в качестве органической целостности, тотальности, системы народной жизни, организованной на началах определенного порядка, в который включается и верховная власть, и государственный аппарат, право и правовой порядок, духовно-нравственные ценности и обычаи, хозяйственная организация вместе с финансовой и налоговой подсистемами, идеология, культура и т. д., а с другой - как исторический феномен, сущность которого постигается на таком уровне абстракции, где соединяются последние достижения не столько теории государства и права, сколько философии, социологии, политологии и геополитики, богословия, культурологии, этики и, собственно, истории, «на современном этапе развития правоведения выходящей на первый план в качестве критерия всеобщности и истинности теоретического обобщения» $[9$, c. 6].

\section{Явление и сущность как философские категории}

Сущзность - это основание и принцип бытия [6, с. 70], то есть самого существования и развития явления. Она составляет смысл данного явления, указывает на то, зачем и для чего оно существует, определяет его постоянные, необходимые и устойчивые качества, без которых оно (явление) перестает быть самим собой и его уже невозможно видеть и мыслить как таковое. Само же явление - это то, что выросло из сущности, видимо проявилось, имеет свое материальное выражение (материю), содержание и форму, присутствует как непосредственное сущее (существо), то есть то, что существует, живет, развивается и умирает, но выступает только временной и одной из возможных модификаций проявления сущности, никогда с нею полностью не совпадает, представляя собой лишь одну из многих форм ее выражения. Отсюда вытекает неразрывная диалектическая связь явления и сущности: явление представляет собой внешнюю форму выражения (проявления) сущности, которая, в свою очередь, как его внутренняя субстанция может быть раскрыта исключительно в явлении. Исходя из этого, форма всегда существенна, а сущность - формирована [10, c. 129]. Однако такое единство явления и сущности не означает их полного совпадения, тождества. Сущность - это внутренняя субстанция (первооснова) явления в противоположность внешним его выражениям, обобщенным в понятии явления [8, с. 154]. Она пребывает в иели явления, как в условии его происхождения, или тесно спаяна с ним, выступая последней, конечной причиной существования явления и его понятия [6, с. 73]. Само бытие явления как определенный порядок событий и действий, в который оно вовлечено, представляет собой процесс раскрытия его сущности, ее становление [1, с. 103], но тем самым истина наличного бытия состоит в том, что оно само есть условие раскрытия всех потенциальных возможностей сущности, достигаемых ее собственным развитием в формальных рамках явления.

Тем самым явление оказывается богаче, объемнее сущности, включая в себя не только свою сущность, но также еще: материю - вещество, из которого состоит явление; форму, как способ организации материи, ее упорядоченную структуру; содержание, как порядок связи и взаимодействия структурных элементов явления между собой, а также с внешней средой, что обусловливает их развитие и позволяет рассматривать содержание явления как процесс. 


\section{Цели как сущностный момент государства}

Быть познанной сущность государства может лишь посредством раскрытия его идеи как гипотетической возможности достижения своего совершенного состояния, в чем и заключается внутренне присущзая государству цель, согласно которой оно развивается, и которая выступает объективным пределом этого развития. Поэтому основным сущностным моментом государства являются иели его происхождения и существования, объективно достижимые и венчающие весь процесс его развития.

Под целью понимается то, ради чего явление или предмет существует [1, с. 96], его назначение относительно более высокой и значимой ценности. Учение о цели и целесообразности существования и развития природных и общественных явлений получило в науке название телеологии (от греч. «телос», «телеос» - результат, цель и «логос» - слово, учение). Ее основы были заложены Аристотелем, развивались в Новое время Лейбницем и получили свое последовательное воплощение в учениях Шеллинга и Гегеля. Согласно этому учению, все предметы и явления объективного мира содержат в себе потенциальную, внутренне присущую им цель существования, которую они стремятся реализовать в процессе своего развития. Сама такая цель рассматривается в телеологии как причина возникновения явления и достижения им своих потенциальных абсолютных возможностей [14, с. 645].

\section{Сущность государства в различных политико-правовых концепциях}

Различные философские и политико-правовые концепции по-разному отвечают на вопрос о ценностях, которым должно служить государство, а следовательно и о целях, которые оно преследует.

В традиционных обществах Древности и Средневековья господствует религиозная доктрина, которая утверждает, что земной мир является результатом проявления трансиендентного мира, порождается им из себя и выступает фактическим продолжением Божественного Начала в земной реальности. Го- сударство представляет собой этносоциальный коллектив, нормативно опирающийся на сложившуюся религиозную традицию собственной культуры государствообразующего народа, и рассматривается как концентрированное выражение и продолжение Божественного в политической организации общества. Поэтому сущность традиционного государства заключается в установлении гармоничного политико-правового порядка, соответствующего божественному космическому порядку во Вселенной, где социально-политическая иерархия на земле во главе с сувереном-монархом соответствует божественной иерархии на небесах. Поэтому государь в религиозных традициях всегда обожествляется, а организация верховной власти стремится к теократии, где политическое руководство осуществляется на основе религиозных норм, а основным субъектом исторического процесса выступает верховная власть. Верховной власти и государству в целом в религиозных традициях (особенно ярко это выражено в православном вероучении) отводится, как минимум, функция удерживающего (по-гречески катехона), способного удержать человечество от власти сына погибели (дьявола, антихриста), с приходом которого ассоциировались процессы хаоса, распада и дезинтеграции общества, деградации и нравственного разложения личности, а как максимум - обеспечение подданным «пространства спасения» - вечной жизни в Царствии Небесном путем организации их праведной жизни на земле - в чем и заключалась основная цель христианского государства $[4 ; 5]$.

В коммунистическом (марксистско-ленинском) учении основным субъектом исторического процесса были общественные классы, а главным двигателем прогресса в развитии общества - классовая борьба. Коммунистическая теория видит в государстве политическую организацию классового господства; машину диктатуры и угнетения одних общественных классов другими; аппарат по управлению делами общества, исходя из интересов экономически господствующего класса. Поэтому сущность государства в соотвествии с марксистской теорией состоит в его служении экономически господствующему класcy, в выражении его политической воли и 
ее навязывании всему обществу. Однако в «Капитале» К. Маркс выдвинул тезис о том, что кроме классовых функций государство, как организация политической власти, выполняет одновременно целый ряд общих дел, вытекающих из природы любого общества (оборона страны, поддержание порядка и т. д.) и отражающих интересы всех или большинства его членов [11, с. 342-346]. Данный тезис был до определенной степени развит социалистическим государствоведением. СССР и другие социалистические страны рассматривались на первом этапе своего существования как государства диктатуры пролетариата в отношении бывших эксплуататорских классов (дворянства, буржуазии). Целевое назначение этого государства заключалось в их ликвидации, построении бесклассового общества и переходе к общенародному государству, где уже должны были отсутствовать социальные классы и происходило постепенное отмирание государства, выполнившего свое целевое предназначение орудия построения коммунистического общества, в котором отсутствует частная собственность и эксплуатация человека человеком, существует полное социальное и экономическое равенство, а люди в силу своей высокой сознательности добровольно исполняют общественные обязанности без особого аппарата принуждения. Результатом становится построение всемирного коммунистического общества, где «вместе с всесторонним развитием индивидов вырастут и производительные силы, и все источники общественного богатства польются полным потоком» [12, с. 20], а «на место управления людьми придет управление вещами» [15, с. 225].

В политической теории либерализма главной иенностью является свобода, а основным историческим субъектом, в интересах которого осуществляется историческое развитие, выступает отдельный человек - индивидуум, освобожденный от всех форм коллективной идентичности: расовой, национальной, религиозной, государственной, семейной, а в конечном итоге и гендерной. Концептуальной основой либерализма выступает теория прав человека, определяющим из которых является право частной собственности. В соответствии с этими ценностями основная цель и назначение либераль- но-демократического государства (других форм государственности либералы не признают, считая, что они не соответствуют критериям экономической эффективности, демократичности и гарантированности прав личности) заключается в обеспечении прав и свобод человека, развитии свободного рынка и институтов гражданского общества. В современной версии либерализма развитие либерально-демократической государственности, к которой должны перейти все страны и народы, в итоге должно привести к их смешению и образованию планетарного гражданского общества с уничтожением религиозных, этнических, национальных и культурных границ с мировым правительством во главе или же без него (здесь существуют различные версии) [2; 3]. Тем самым за последние два столетия западная элита постепенно трансформировала идеологию либерализма и практику строительства либерально-демократической государственности в теорию экономической глобализации и практику построения однополярного мира с одним единым центром власти и управления, с посткапиталистическим общественным строем, основанным на монопольном господстве глобальной олигархии и внеэкономическом распределении ресурсов, информации и всех остальных благ, где «обеспеченное существование на планете может быть гарантировано только для миллиарда человек из наиболее преуспевающих стран, в то время как всем остальным странам уготована жалкая участь сырьевого придатка и поставщика дешевого человеческого материала для обслуживания интересов транснационального капитала» [7, с. 137-138] (концепция так называемого «золотого миллиарда»).

В этом своем аспекте либерализм во многом совпадает с марксистской утопией отмирания государства. Однако если марксизм связывал такое отмирание с построением коммунистического общества, которое должно было стать обществом социальной справедливости, то новый постлиберальный порядок весьма напоминает кастово-жреческую организацию восточной деспотии древности в ее постсовременном виде, осуществляющую свое господство на основе высоких наукоемких информационно-когнитивных технологий. 


\section{ТЕОРИЯ И ПРАКТИКА ГОСУДАРСТВЕННО-ПРАВОВОГО РАЗВИТИЯ}

\author{
Сущность государства \\ как производное телеологии, \\ метафизики и диалектики
}

По существу и социалистическое, и либерально-буржуазное учения о сущности государства носят идеологический характер. В их основе находится стремление доказать преимущество определенного устройства государства и общества по отношению к своим политическим и идеологическим противникам, а не поиск объективной природы государства как социально-политического организма, что предполагает необходимость подхода к нему как системному, целостному явлению, органическому единству своих сущности, материи, формы и содержания.

При таком рассмотрении государства его материя будет включать в себя следующие вещественные элементы: а) территориальный - землю и почву, природные ресурсы и т. д., то есть вмещающий ландшафт, который является для государства непосредственным источником материальных ресурсов, используемых обществом посредством своих экономических, производственных и технологических механизмов в целях своего хозяйственного развития; б) этносоциальный-население, именно как этносоциальный субстрат государства, приспособленный к жизни и ведению хозяйственной деятельности в настоящем географическом ареале, имеющим его в качестве своего месторазвития; в) экономический - система хозяйства материальные ресурсы, хозяйствующие субъекты, средства производства, производственная структура и процесс производства и распределения материальных благ, производственная инфраструктура (дороги, транспорт, связь, складские помещения и др.) и т. д.; г) политический-система власти и управления - государственные органы и учреждения, государственные служащие, депутаты, полиция, ИТУ и т. д.; д) нормативный - право, законодательство, моральные и религиозные нормы, обычаи и обыкновения, политические традиции, правоприменительная практика и т. д.

Все эти материальные элементы объединяются в единую политико-правовую целостность благодаря государственной фор- ме. Материя в данном случае выступает как основа или субстрат формы. Государственная форма, в свою очередь, сообщает достаточно рыхлой территориальной, этносоциальной, экономической, нормативной материи вполне оформленное устойчивое содержание. Форма государства является одним из важнейших проявлений содержания и сущности государства, его главнейшим атрибутом. Она не существует сама по себе и не может складываться произвольно в соответствии с желаниями и представлениями правящих кругов, но всегда обусловлена своим содержанием и находится в тесной связи и взаимозависимости с материальными атрибутами государственности - вмещающим ландшафтом, условиями хозяйственной жизни, народом, традициями власти и управления, правовыми обычаями и т. д.

Содержание государства - это упорядоченная государственной властью материя, которая представляет собой устойчивую совокупность политических, экономических, правовых и др. связей, отношений, процессов, образующих в своей совокупности государственную жизнь. Содержание государственной жизни включает в себя иели внутреннего и внешнего развития государства, его перспективные и краткосрочные задачи, функции государства, его аппарата и органов, механизм власти и управления общественной жизнью, политикоправовой порядок, различного рода связи между верховной властью и народом, государственным аппаратом и различными социальными и региональными общностями и коллективами, саму систему социальных отношений в государственно-организованном обществе и его международные связи как форму реализации его суверенитета.

Для выяснения действительной сущности государства необходимо учесть и использовать одно важное обстоятельство методологического характера. Оно заключается в адекватном подходе к самомому процессу познания государства, в котором, как показали представители диалектического метода, человеческая мысль, бесконечно углубляясь, движется от лежащих на поверхности явлений к их сущности, от сущности первого порядка к сущности второго порядка и т. д. без конца вплоть до самой основы явления, под 
которой понимается наиболее глубокий момент сущности [10, с. 227], представляющий собой неизменный, метафизический первопринцип, выявляющий истинную сущность предмета. Здесь диалектика смыкается с метафизикой, вытекает из нее, совсем не противореча ей, а напротив, дополняя. Именно такой подход был использован С.Н. Бабуриным, который выделил четыре уровня сущности государства: политический, классовый, общесоциальный и религиозный, предполагающий наличие в истории Божьего Промысла. При этом основоположников материалистической диалектики можно упрекнуть в том, что при анализе сущности государства сами они отошли от диалектического метода, так и не добравшись до ее наиболее глубокого момента, поскольку не выяснили какой основополагающей ценности призвано служить государство и не выявили его последнего основания.

Только при первом поверхностном взгляде секуляризированного эгоистического сознания, для которого свое личное «я» есть мера всех вещей, может показаться, что государство создается для блага каждого конкретного человека, обеспечения его прав, свобод и интересов. Если и можно увидеть в этом сущность государства, то ее, и то только чисто логически (но не исторически), следует рассматривать лишь как сущность первого порядка - антропологическую.

Человек - это существо исключительно общественное, всегда существующее в конкретной среде семьи, трудового коллектива, населенного пункта, нации и т. д., раскрывающее свои качества и способности только в отношениях с другими людьми. Общественное является для него естественной и по сути единственной средой его бытия. Но основной формой существования общества является государство, осуществляющее его политическую интеграцию и обеспечивающее единство всех его разнородных элементов и сторон жизни. Его бытие есть особого рода коллективная жизнедеятельность составляющих его людей. Поэтому государство не может ставить своей целью достижение частных интересов и частного блага. Цель государства, как подчеркивают многие исследователи (начиная с Платона, Аристотеля и Конфуция), общая, а не частная - это достижение общего блага, которое заключается в обеспечении интересов общественного целого против угрожающих им частных интересов. Этот осознанный публичный интерес включает в себя также целый ряд частных и групповых интересов, которые невозможно реализовать, не удовлетворив общий. И заключается он в обеспечении единства, упорядоченности, иелостности, устойчивости и самом существовании, воспроизводстве и развитии государственно-организованного общества и составляющего его народа. Исходя из того, что всякое иное, кроме чисто логического обособление человека от общества невозможно, антропологическая, чисто человеческая сущность государства плавно переходит в онтологическую, которая выступает как сущность второго порядка. Коротко ее можно определить следующим образом: государственная форма обеспечивает политическое единство и правовой порядок для этнически, соииально и конфессионально дифференцированного общества, поскольку внешнее существование государства, его бытие в международных отношениях происходит в форме нерасчлененного суверенного политического единства.

Однако, выступая таким образом на международной арене, по своей внутренней социально-политической структуре и первоначальной природе государство остается организацией сословно-классовой, обеспечивающей господство одних групп и слоев населения над другими и выражающей их материальные интересы. Исторически каждое конкретное государство создавалось как господство организованного меньшинства над неорганизованным большинством в целях его экономической эксплуатации и выступало, прежде всего, как организация социального принуждения. Причем очень часто это происходило посредством порабощения одних этносов другими, и лишь впоследствии социальное развитие приводило к национальному слиянию и формированию единого государствообразующего народа. Но и он имеет всегда иерархическую структуру, в которой руководящая роль принадлежит политико-административной и хозяйственной элите, политически и (или) экономически господствующим классам, осуществляющим государственную власть и уп- 


\section{ТЕОРИЯ И ПРАКТИКА ГОСУДАРСТВЕННО-ПРАВОВОГО РАЗВИТИЯ}

равление, исходя в первую очередь из своих социально-экономических интересов. В этом находит свое проявление сословно-классовый характер государства, служащий выражением его внутренней, социальной сущности, которую можно обозначить как сущуность третьего порядка.

Социальная иерархия является необходимым атрибутом государственно-организованного общества, выступая его ответом на процессы энтропии и разложения в нем, возвращая его к состоянию устойчивости и равновесия. В то же время она вызывает социальные противоречия и классовую борьбу в обществе. Поэтому основной задачей внутренней политики верховной власти государства является примирение социальных классов, достижение согласия и солидарности в отношениях различных слоев населения на основе принципа социальной справедливо$\mathrm{cmu}$, сохранение и укрепление политического единства и целостности государства как суверенного субъекта международных отношений. Это предполагает наиболее полное согласованное существование, сочетание и развитие всех элементов и частей государства, приведение их к высшему гармоничному единству в составе целого. В стремлении к такой гармонии заключается внутренняя идеальная иель государства, которая включает в себя и мир, и свободу, и порядок, и общее благо как высшее осуществление справедливости и правды на Земле.

Однако установление справедливого порядка социальных отношений в государстве может быть основано лишь на определенном национальном идеале, то есть вполне конкретных сочиально-нравственных иеннос$m я x$, свойственных именно данному государствообразующему народу, которые сохраняют свою значимость и духовную преемственность в его жизни на протяжении многих поколений, неизменно проявляют себя в политических и правовых институтах, формах государственной организации, могущих иметь между собой на отдельных этапах исторического развития значительные внешние различия. Реальная действенность таких идеалов определяется только тем, что государство служит базовым иенностям государствообразующего народа и утверждает себя как организачия, созданная для их осуществления. В этом заключается еще один уровень сущности государства - национально-культурный (цивилизационный). Процессы реформирования и модернизации государства ни в коем случае не должны затрагивать базовые ценности государствообразующего народа, выраженные в его национальном идеале. Такие ценности представляют собой «центральную зону» культуры всякого государственно-организационного общества и содержат в свернутом, обобщенном виде все его традиции, символы, верования, упорядочивают их, определяя тем самым природу сакрального в обществе. Они имеют общесоциальное значение. Только их наличие делает возможным само существование и воспроизводство нации и государства [13, с. 310-312]. Более того, формирование государствообразующего народа и его политическое отделение от других наций происходят исключительно посредством собственного национального, нравственного и политико-правового идеала, который является зеркалом его собственной цивилизационной идентичности, консолидирующим и скрепляющим началом. Сохранение и воспроизводство национального идеала одновременно является гарантией стабильности и условием проведения модернизации в необходимых для этого случаях.

Справедливый порядок и строй народной жизни составляет идеальную внутреннюю политическую сущность государства и подлинное содержание государственной деятельности. Однако никакое государство не пребывает в мире в одиночестве, и вопрос о его настоящем и будущем существовании всегда решается соотношением его сил с силами других государств на международной арене, а не просто на основе собственной (внутренней) упорядоченности. Поэтому кроме внутренней цели любое здоровое и сильное государство имеет и свою внешнюю цель, связанную с его положением среди других политических сообществ. Эта цель заключается в обеспечении самостоятельного и независимого существования государствообразуюшего народа (нации), его внешней свободы по отношению к другим начиям $u$ народам. При этом данный народ посредством национальной идеологии - политичес- 
кой мифологии, религиозной и (или) правовой доктрины, вырабатываемых на основе общих идеалов и ценностей - сам определяет, в чем заключается его свобода, самостоятельность и независимость, их конкретное содержание, не всегда, может быть, ясно осознаваемые, но всегда очень остро ощущаемые. Практически эта иель состоит в стремлении обладать геополитическим могуществом, внешней мощью, что является верховным законом бытия всякого, не столько юридически, сколько фактически суверенного государства. Фактический полный внешний суверенитет (внешняя независимость и самостоятельность) составляет идеальную внешнюю иель и геополитическую (внешнеполитическую) сущность государства.

Внутренние и внешние идеальные цели государства тесно взаимосвязаны. Самостоятельное и независимое существование государства невозможно без реализации в общественной жизни базовых ценностей образующего его народа, выраженной в организации хотя бы минимально справедливого политико-правового порядка. При этом внутренняя упорядоченность собственного строя жизни выступает средством обеспечения основной внешней цели государства и наоборот. Реализация социально-нравственного идеала предполагает внешнюю самостоятельность, независимость и наличие государственной мощи как гарантий построения справедливо организованного общества, и все вместе это обеспечивает существование, воспроизводство, благополучие и проиветание государствообразующего народа. Из целей государства вытекает содержание внешних и внутренних функций, задач и направлений деятельности государства, его аппарата и органов, посредством которых они объективируются и реализуются на практике вместе со своей внутренней организацией и системой внешних связей.

\section{Выводы}

Таким образом, именно в идее полного фактического суверенитета заключается сущность государства как социально-политического феномена, включающая в себя все его остальные сущности. Без стремления к ее реализации этносоциальный субстрат государства, государствообразующий народ не сможет достичь политико-правового единства, обеспечить наличие и сохранность своего государственного статуса, гарантировать внутреннюю упорядоченность, справедливый мир и согласие, не сможет создать условия для обретения необходимой внешней мощи и культурного роста, а следовательно обеспечить свое выживание, воспроизводство и развитие, то есть само существование государства как идеальной политической сущности.

Суверенитет - это тот элемент содержания и та сторона формы государства, что придает ему бытие как явлению, ведя его по пути самоопределения и достижения наиболее полной степени самодостаточности во всех отраслях и сферах своей жизнедеятельности; он никоим образом не отделим от государства, которое, лишившись его, перестает быть государством. Поэтому государство и суверенитет, взятые в своих потенциально имманентных целях и возможностях существования, суть синонимы.

\section{СПИСОК ЛИТЕРАТУРЫ}

1. Аристотель. Метафизика // Аристотель. Сочинения : в 4 т. Т. 1. - М. : Мысль, $1975 .-550$ с.

2. Аттали, Ж. Краткая история будущего / Ж. Аттали. - СПб. : Питер, 2014. - 288 с.

3. Бек, У. Власть и ее оппоненты в эпоху глобализма. Новая всемирно-политическая экономия /У. Бек. - М. : Прогресс-Традиция: Территория будущего, 2007. -464 с.

4. Библия: Книги священного писания Ветхого и Нового Завета. - М. : Издательство Московской Патриархии, 1992. - 1372 c.

5. Величко, А. М. Библейская философия права и власти / А. М. Величко, протоирей Тимофей Фетисов. - М. : Вече, 2016. - 192 с.

6. Гегель, Г. В. Ф. Наука логики : в 3 т. Т. 2. Кн. 2. Учение о сущности / Г. В. Ф. Гегель. - М. : Мысль, 1971.- 248 с.

7. Глазьев, С. Ю. Геноцид / С. Ю. Глазьев. M. : TEPPA, 1998. $-320 \mathrm{c}$.

8. Керимов, Д. А. Методология права: Предмет, функции, проблемы философии права / Д. А. Керимов. -М. : Изд-во СГА, 2003. $-521 \mathrm{c.}$

9. Лейст, О. Э. Сущность права. Проблемы теории и философии права / О. Э. Лейст. - М. : Зерцало-М, 2002.- 288 c. 


\section{ТЕОРИЯ И ПРАКТИКА ГОСУДАРСТВЕННО-ПРАВОВОГО РАЗВИТИЯ}

10. Ленин, В. И. Философские тетради / В. И. Ленин // Ленин В. И. Полн. собр. соч. Т. 29. - М. : Госполитиздат, 1963. - 785 c.

11. Маркс, К. Капитал. Критика политической экономии. Т. 1. Кн. 1. Процесс производства капитала // Маркс К., Энгельс Ф. Соч. Т. 23. - М. : Госполитиздат, 1962. - $907 \mathrm{c.}$

12. Маркс, К. Критика Готской программы // Маркс К., Энгельс Ф. Соч. Т. 19. - М. : Госполитиздат, 1961.-С. 10-32.

13. Поляков, А. В. Общая теория права: Феноменолого-комуникативный подход / А. В. Поляков. - СПб. : Юридический центр Пресс, 2003. $845 \mathrm{c}$.

14. Философский энциклопедический словарь / редкол. С. С. Аверинцев, Э. А. Араб-Оглы, Л. Ф. Ильичев [и др.]. - М. : Сов. энциклопедия, 1989. -815 с.

15. Энгельс, Ф. Развитие социализма от утопии к науке // Маркс К., Энгельс Ф. Соч. Т. 19. - М. : Госполитиздат, 1961. - С. 185-230.

\section{REFERENCES}

1. Aristotel. Metafizika [Aristotle. Metaphysics]. Aristotel. Sochineniya: v 4 t. T. 1 [Aristotle. Compositions: in 4 vols. Vol. 1.]. Moscow, Mysl Publ., $1975.550 \mathrm{p}$.

2. Attali Zh. Kratkaya istoriya budushchego [A Brief History of the Future]. Saint Petersburg, Piter Publ., 2014. 288 p.

3. Bek U. Vlast $i$ ee opponenty $v$ epokhu globalizma. Novaya vsemirno-politicheskaya ekonomiya [Power and Its Opponents in the Era of Globalism. New World-Political Economy]. Moscow, Progress-Traditsiya Publ.; Territoriya budushchego Publ., 2007. 464 p.

4. Bibliya: Knigi svyashchennogo pisaniya Vetkhogo i Novogo Zaveta [The Bible: Books of the Holy Scriptures of the Old and New Testaments]. Moscow, Izd-vo Moskovskoy Patriarkhii, 1992. 1372 p.

5. Velichko A.M. (archpriest Timofey Fetisov) Bibleyskaya filosofiya prava $i$ vlasti [Biblical
Philosophy of Law and Power]. Moscow, Veche Publ., 2016. 192 p.

6. Hegel G.V.F. Nauka logiki: v 3 t. T. 2. Kn. 2. Uchenie o sushchnosti [The Science of Logic: in 3 vols. Vol. 2. Book 2. The Doctrine on the Essence]. Moscow, Mysl Publ., 1971. 248 p.

7. Glazyev S.Yu. Genotsid [Genocide]. Moscow, TERRA Publ., 1998. 320 p.

8. Kerimov D.A. Metodologiya prava: Predmet, funktsii, problemy filosofii prava [Methodology of Law: Subject, Functions, Problems of Philosophy of Law]. Moscow, Izd-vo SGA, 2003. 521 p.

9. Leyst O.E. Sushchnost prava. Problemy teorii i filosofii prava [The Essence of Law. Problems of Theory and Philosophy of Law]. Moscow, Zertsalo-M Publ., 2002.288p.

10. Lenin V.I. Filosofskie tetradi [Philosophical Notebooks]. Lenin V.I. Poln. sobr. soch. T. 29. [Lenin V.I. Complete Collection of Works. Vol. 29]. Moscow, Gospolitizdat Publ., 1963. 785 p.

11. Marx K. Kapital. Kritika politicheskoy ekonomii. T. 1. Kn. 1. Protsess proizvodstva kapitala [The Capital. Criticism of Political Economy. Vol. 1. Book 1. The Process of Capital Production]. Marx K., Engels F. Soch. T. 23 [Works. Vol. 23]. Moscow, Gospolitizdat Publ., 1962. 907 p.

12. Marx K. Kritika Gotskoy programmy [Critique of the Gotha Program]. Marx K., Engels F. Soch. T. 19 [Works. Vol. 19]. Moscow, Gospolitizdat Publ., 1961, pp. 10-32.

13. Polyakov A.V. Obshchaya teoriya prava: Fenomenologo-komunikativnyy podkhod [General Theory of Law: Phenomenological-Communicative Approach]. Saint Petersburg, Yuridicheskiy tsentr Press, 2003. 845 p.

14. Averintsev S.S., Arab-Ogly E.A., Ilyichev L.F., et al. (eds.) Filosofskiy entsiklopedicheskiy slovar [Philosophical Encyclopedic Dictionary]. Moscow, Sov. entsiklopediya, 1989.815 p.

15. Engels F. Razvitie sotsializma ot utopii k nauke [The Development of Socialism from Utopia to Science]. Marx K., Engels F. Soch. T. 19 [Works. Vol. 19]. Moscow, Gospolitizdat Publ., 1961, pp. 185-230.

\section{Information about the Author}

Nikolay I. Grachev, Doctor of Juridical Sciences, Professor of Department of Civil and Private International Law, Volgograd State University, Prosp. Universitetsky, 100, 400062 Volgograd, Russian Federation, gimchp@volsu.ru.

\section{Информация об авторе}

Николай Иванович Грачев, доктор юридических наук, профессор кафедры гражданского и международного частного права, Волгоградский государственный университет, просп. Университетский, 100, 400062 г. Волгоград, Российская Федерация, gimchp@volsu.ru. 